\title{
Project Executive's Ethical Leadership and Construction Projects' Social Responsibility: Evidence from Wuhan, China
}

\author{
Jintao Li $\mathbb{D}^{1,2}$ Wei Ying ${ }^{1}{ }^{1,2}$ Rao Xiong, ${ }^{3}$ and Chi Ying ${ }^{4}$ \\ ${ }^{1}$ School of Civil Engineering, Architecture and Environment, Hubei University of Technology, Wuhan 430068, China \\ ${ }^{2}$ Innovation Demonstration Base of Ecological Environment Geotechnical and Ecological Restoration of Rivers and Lakes, \\ Hubei University of Technology, Wuhan 430068, China \\ ${ }^{3}$ Statistics \& Data Science, University of Arizona, Tucson 85719, USA \\ ${ }^{4}$ College of Computer Science and Electronic Engineering, Hunan University, Changsha 410082, China
}

Correspondence should be addressed to Wei Ying; leavell691@hbut.edu.cn

Received 26 October 2021; Revised 13 January 2022; Accepted 31 January 2022; Published 21 February 2022

Academic Editor: Morteza Bagherpour

Copyright ( 92022 Jintao Li et al. This is an open access article distributed under the Creative Commons Attribution License, which permits unrestricted use, distribution, and reproduction in any medium, provided the original work is properly cited.

With the accelerated urbanization and the need for sustainable development in China, the construction projects' social responsibility (CPSR) has received increasing attention from scholars, but reliable empirical evidence on whether the project executive's (PE's) ethical leadership can promote the implementation of the CPSR is insufficient. This study constructs a moderated mediation model in which we examine the role of employees' organizational identification and organizational justice in the relationship between the PE's ethical leadership and the organizational CPSR through data of 367 samples collected validly. Through the research, we found that the PE's ethical leadership has a positive impact on the CPSR, the employee's organizational identification mediates the relationship between the PE's ethical leadership and the organizational CPSR, and organizational justice moderates between the PE's ethical leadership and employee's organizational identification. The outcomes indicate that the PE's ethical leadership can promote the implementation of the organizational CPSR. This study reveals the intrinsic action mechanism of the PE's ethical leadership and the implementation of the organizational CPSR, which has certain implications for improving the performance of CPSR and achieving the sustainable development of the projects.

\section{Introduction}

The accelerated technological development and urbanization in China today have stimulated the demand for project construction, and the implementation and operation of constructional projects have extensively promoted the development of society, economy, and technology. By 2020, China's construction industry has employed 54,270,800 people, and the total output value has reached 24.84 trillion CNY. The mega construction projects (megaprojects) have gained attention by researchers, but while improving the quality of life, a few negative social events have also been caused by abundant regular construction projects impelled by a new type of urbanization in China. As reported by the media, some constructions of real estate and office buildings in bustling downtown have damaged the surroundings and life of nearby residents because of the lack of social responsibility of projects participants. The rights protection of proprietors sometimes happens due to inadequate quality control. Arrears of wages by contractors from the vicious competition and inappropriate control of cost and the deaths and injuries in the collapse of the operating platform caused by the weak awareness of safety had also been reported frequently. The concept of social responsibility should then be introduced into the construction projects to reduce the environmental damages and negative social events from the cycle of construction projects $[1,2]$. However, in the construction industry, only $9.6 \%$ of corporations have independent social responsibility assessments, according to research on corporate social responsibility implementation. Most corporations do not have a formal policy or strategy relating to social 
responsibility. The research also indicates that the awareness of social responsibility among construction industry practitioners is low, and most of the respondents only recognized economic responsibility as the essential element of social responsibility [3,4]. Although Wang et al. [5] raised that supervising the project implementation process through public participation in project construction can improve the implementation of CPSR, the actual level of public participation in project construction is still low due to the closed and exclusionary nature of the project. It has been proved that the environmental responsibility of participants can benefit the spontaneous environmental protection of stakeholders and hence benefit the public [6]. The fulfillment of social responsibility is a critical factor that enables the construction industry to achieve the goal of sustainable development $[7,8]$, as well as an effective means of enhancing project performance [9]. Therefore, promoting the implementation of the CPSR and identifying the drivers of the CPSR have received increasing attention from scholars.

Researchers have explored the mechanisms of the CPSR implementation at three different levels in the previous studies. From the macro level, the implementation of the CPSR is influenced by regulatory pull, ethical push, economic support, and political foundation, among which regulatory pull is the most sustainable, effective, and reliable driving force for the CPSR by regulating the behavior of construction project stakeholders from top to bottom through laws and regulations [10-12]. From the perspective of the corporations involved in the construction of the project, the corporate size, corporate strategy, corporate profitability, and the smooth communication between the participating stakeholders will affect the implementation of the CPSR [13-15]. From the level of leader's characteristics, PE's straightforwardness, cognitive of social responsibility, openness to new things, and competency of work can promote the implementation of the CPSR to varying degrees [16]. On the other hand, the narcissism of CEOs could exaggerate their ability, which is adverse to understanding the connotation of social responsibility and implementing the CPSR, while public concern can suppress this influence effectively [17]. The results of these previous studies have increased our understanding of the factors influencing CPSR implementation, especially from the level of leader's characteristics. Nevertheless, as the characteristics, competency, and narcissism have already gained attention from scholars, one crucial aspect is missing in these researches: PE's leadership style. Therefore, it is worthy of further investigation of the promotion of the implementation of social responsibility from the PE's ethical leadership, which can help the decision-making at the leader's level and give preferable instruction on the implementation of CPSR.

To fill in the gaps of former researches, this study discusses whether and how ethical leadership by PEs plays a role in improving the implementation of the CPSR in organizations. Compared with macro strategy and corporation's attributes, which are factors that cannot be controlled, PE's ethical leadership is more sensitive to the restriction of internal regulations. Through effective decisions, the implementation of social responsibility can be enhanced, and the negative social impacts, from quality, safety, and the environment caused by the projects in the construction process, can be reduced. To clarify the relationship between the PE's ethical leadership and the CPSR of the organization, we conducted a questionnaire targeting the management organizations involved in project construction in Wuhan from January to April 2021, expanded the scope of data collection through an online research platform, and finally used the Process macro in SPSS to test the theoretical model this study proposed. The study contributes mainly from two aspects: first, while previous studies mainly focus on the effect of institutional pressure and leader's characters on the implementation of the CPSR, this study, based on the upper echelons theory and previous research results, examines the relationship of the PE's ethical leadership with the organizational CPSR from the aspect of leader's leadership style and enriches the research with the impact of the CPSR from the personal level of leaders. Second, we reveal the intrinsic action mechanism between this relationship, considering the role of employees involved in project management in implementing the CPSR. The results of this study have a particular reference value and significance for exploring how to implement the CPSR from the level of individual leaders. While construction projects have public attributes as the behavior of project participants in the construction process is closely related to the general public, raising the degree of implementation of the CPSR can help improve project quality and environmental protection awareness, reduce construction costs from the project level, improve the regional economy, drive economic development, and promote employment from the macroeconomic level. It helps to realize the organizational CPSR by disciplining the behavior of PEs and promoting their ethical approach to leadership.

Below is the rest of the study. Section 2 describes the CPSR and its conceptual framework. Then Section 3 is variable measurement and data collection. Section 4 is the variable reliability and validity analysis and hypothesis testing. The results are discussed in Section 5. Finally, Section 6 presents conclusions, policy implications, and future research recommendations.

\section{Literature Review and Hypothesis Development}

2.1. Construction Projects' Social Responsibility. The main object of the concept of social responsibility, first proposed by Sheldon in 1924, was the corporation [18]. In addition to meeting the development needs, corporations should formulate strategies and make decisions following the goals and values expected by society [19]. In particular, megaprojects received widespread concern from researchers with their more complex dynamic and participants of stakeholders compared to regular construction projects. Megaprojects usually include the infrastructural project with significant influence on the economy, environment, and society, such as roads, railways, large bridges, and other public projects. Zeng et al. (2015) took major infrastructure projects as the research object and brought up that a comprehension 
framework consisting of "stakeholder-project's life cyclesocial responsibility" should be established combining the characteristics of major infrastructure projects and intention of social responsibility. They defined the megaprojects social responsibility (MSR) as the "responsibility taken by the stakeholders of a megaproject for the social and environmental impact of their decisions and activities, through the transparent and ethical behavior throughout the life cycle of the project" [1]. However, the definition of "megaprojects" in current academics varies, and the amount invested in projects is a wildly used index. For example, the investment amount of megaprojects should exceed 500 million EUR or 1 billion USD in developed countries [20,21]. Nevertheless, $\mathrm{Hu}$ et al. [22] suggest megaprojects should be defined based on the economic development in the country. In China, some researchers believe megaprojects should be the projects for more than 1 billion CNY [23, 24], while, as provisioned by law, projects more than 25 floors or with investment exceeded 100 million CNY should be classified as megaprojects. Thus, it is hard to define megaprojects because of the construction projects' inherent complexity and dynamics [25].

Megaprojects are usually related to the national macro strategies, and MSR is viewed as the responsibility in national economic growth, industry development, and job creation [1]. Lin et al. [2] believe an integrated index system should still be built for even megaprojects to direct the implementation of MSR from the decision level. Specifically, the implementation of MSR should take the economy, law, ethics and environment, and politics, in a total of four dimensions, into consideration on both organization and projects levels: I) the economic dimension includes project quality, schedule, safety, cost, etc.; II) legal dimension includes fair competition, law compliance, etc.; III) ethical and environmental dimensions include pollution prevention, ecological protection, worker safety, health, etc.; IV) political responsibility then includes job creation, philanthropy, and others $[2,17,26]$. Among these, quality and safety have been concerned as the most important by stakeholders of MSR, while philanthropy is less critical since it can be used to veil the misconduct of projects participants [2]. While quality and safety are vital considerations for all construction projects, this research result helps evaluate regular construction projects. Moreover, Lin et al. [17] and Ma et al. [8] state that the index system can be used to evaluate projects with less than 100 million CNY investments and make the evaluation of CPSR possible.

The construction project has a certain degree of complexity over stakeholders as it requires the effort from many parties to achieve the construction goal, and thus which stakeholders' roles are essential has been concerned wildly [27]. Since the contractor's role is critical in the project implementation process, the community, $\mathrm{CEO}$, project management team, and clients are the critical stakeholders in the project-level stakeholder identification research conducted mainly by the contractor [28]. The corporatelevel stakeholders include stockholders, clients, employees, suppliers, subcontractors, community, and government [29]. At the entire project life-cycle level, internal stakeholders with contractual relationships, such as government, owner, contractor, and supervisor, are usually key factors in the CPSR implementation. While the government and the developer dominate the decision-making, contractors dominate the project implementation phase, and the supervisor's control over social responsibility issues is relatively high in both the decision-making and implementation phase and is minimized in the completion phase $[30,31]$.

Other research has been conducted on contractors, focusing on the factors driving the fulfillment of social responsibility in the construction industry. Researches have shown that leadership traits and support from senior management are critical factors contributing to the successful implementation of social responsibility. For example, in research of whether construction corporations adopt social responsibility, Zahidy et al. [32] found that senior management and financial resource support was the most important factor. In construction corporations, social responsibility is hard to implement due to senior management's lack of support [33]. Mayr [34] found that construction corporate leaders' values and ethical beliefs play a critical role in social responsibility strategies. Li et al. [35] found that ethical leadership is vital to the social responsibility strategy of construction corporations, and institutional pressure can motivate managers with higher ethical levels better, which is consequently more conducive to promoting the formulation of social responsibility strategies in construction corporations. Mandatory institutional pressure can inspire ethical leadership and promote corporate social responsibility strategies.

These researches have enriched our understanding of the CPSR, but there is still little research from the PE's ethical leadership perspective, which leaves space for further development. Specifically, there have been few studies on the relationship between CPSR implementation and PE's ethical leadership as well as the function of organizational identification of managers involved in project construction in the organizational CPSR implementation. Accordingly, this research, using upper echelons and affective event theories, examines the mediated effect of the employee's organizational identification on ethical leadership and the CPSR at the organizational level, as well as organizational justice's moderating role, from the interaction between the PE's ethical leadership and the employee's organizational identification.

\subsection{PE's Ethical Leadership and CPSR. A construction} project is a temporary contractual organization consisting of personnel from different departments or specialties from multiple corporations involved. It is set up around the construction task [36], with the characteristics of organizational temporality, team diversity, and task complexity [37]. The project executives (PEs) referred to in this research are the heads of owners, contractors, supervisors, and other corporations in the project, and therefore in conjunction with the notion of ethical leadership, the definition of PE's ethical leadership is 
conducting activities ethically in personal behavior and interactions of the PE. Due to the temporality of construction projects, these heads usually have relatively large discretionary powers. For example, the leadership style of the project manager can significantly affect project performance [38]. Meanwhile, upper echelons theory also states that the characteristics of senior managers in an organization determine their behavioral preferences in work, thus influencing the organization's decisions and outcomes [39]. Leaders, as ethical individuals, have a broad moral consciousness with high levels of ethical leadership, including thinking about others, respecting others, and having the qualities of honesty, integrity, consistency in word and deed, and sincerity. As ethical managers, they emphasize managing ethically, abiding by laws and regulations, and setting ethical standards in the organization, and their decisions reflect the best interests of the organization $[40,41]$. This fits in with the concept of the CPSR because sophisticated ethical leaders perform better on complying with regulations, concerning problems such as environment protection and others, and paying attention to employees' rights. Some previous studies have found that the characteristics of leaders are crucial for implementing social responsibility; construction corporations' social responsibility strategies depend to a great extent on the moral beliefs and ethical leadership of leaders [34,35]; and the values, competence, and narcissism of leaders affect the CPSR implementation to varying degrees [16, 17]. Accordingly, we proposed the first hypothesis in this research as follows:

Hypothesis 1 (H1): the PE's ethical leadership correlates positively with the organizational CPSR.

2.3. Employee's Organizational Identification. Employee's organizational identification refers to the cognitive process that generates the emotions in the working process, and it is also a perception of self-affiliation to the group [42]. Organizational identification as a variable of employees' identification of the value of an organization and internalization of the organization can explain the psychological connection and mechanism of the actions between employees and the organization [43]. Morgan et al. [44] found that a stable and harmonious link between the leaders and employees promotes organizational identification among employees. Ethical leaders demonstrate ethical behavior in their actions and interpersonal interactions, as they value their employees' interests and personal needs and promote organizational identification by setting an ethical role model for their employees. According to the affective events theory, the ethical behavior of leaders affects the emotional status of employees and triggers their moral identification. When employees perceive the ethical behavior of leaders in the organization, the psychological distance between employees and the organization can be shortened, and then the employee's identification and belongingness can be enhanced [45]. Thus, the PE's ethical leadership may positively affect employees' organizational identification. In addition, employees' organizational identification can predict their working attitudes and behaviors. On the one hand, organizational identification can enhance the accuracy of employees' identity within the organization and their awareness of goals; on the other hand, organizational identification can enhance employees' sense of identification within the organization and thus maintain consistency with the organization. Previous researches have shown that employee's organizational identification promotes organizational citizenship behavior [46], loyalty behavior [47], proactive and responsible behavior [48], and job dedication [49]. As the important participants in project management, the attitudes and behaviors of the members of project management organizations affect the organization's results. Specifically, members of project management organizations with high organizational identification will take the initiative to engage in positive and responsible behavior in managing projects, thus effectively contributing to the CPSR implementation. Accordingly, the following hypothesis is proposed:

Hypothesis 2 (H2): the relationship between PE's ethical leadership and CPSR of the organization is mediated through employees' organizational identification.

2.4. Organizational Justice. Organizational justice refers to the perception of fairness of members regarding policies, institutions, and measures related to individual interests. It contains justice from two dimensions: distributive and procedural. Distributive justice affects more on the subjective attitudes of members in the organization, for example, employees' satisfaction with salary or job; while procedural justice is an individual's assessment of the justice of the implementation of organizational procedures, which is more closely related to organization-directed responses [50]. Based on affective event theory, the perception of organizational injustice can be seen as a pressure that will trigger negative emotions in employees [51]. Under such negative emotions, employees are less likely to identify with some decisions made in the organization, whereas high organizational justice perceptions promote employees' identification with the organization. In addition, the traits of ethical leaders (honesty, integrity, and justice) also affect organizational justice to some extent. Thus, organizational justice may moderate between the PE's ethical leadership and organizational identification of employees. As Wen and Ye [52] stated, when the first half of the mediating path is moderated by the moderating variable, this mediating effect can also be moderated. For this research, the PE's ethical leadership is more likely to enhance the implementation of organizational CPSR by promoting the organizational identification of employees with higher perceptions of organizational justice. Accordingly, the following hypotheses are proposed in this research:

Hypothesis 3 (H3): Organizational justice moderates the relationship between the PE's ethical leadership and employee's organizational identification. 
Hypothesis 4 (H4): Organizational justice moderates the mediation strength of employee's organizational identification.

In summary, this study's conceptual model is shown in Figure 1.

\section{Method}

3.1. Measurements. The variables measured in this research were the PE's ethical leadership, employee's organizational identification, organizational justice, and the organizational CPSR. A 5-point Likert scale was adopted in the questionnaire.

PE's ethical leadership: the scale used by Brown et al. (2005) was adopted, which contains10 items. Since we found some respondents misunderstood "leader" as their supervisor, such as the technical director of engineer, to better measure the ethical leadership of PEs (who in charge of the project), the word "leader" was replaced by "executive" in the items, with specific items such as "My executive sets an example of how to do things the right way in terms of ethics", with the suggestion from respondents and experts.

Employee's organizational identification: Mael and Ashforth's (1992) scale was adopted, containing 6 items, with specific items such as "I am very interested in what others think about my project management organization".

Organizational justice: referring to the distributive and procedural justice in the organizational justice scale developed by Liu et al. [53] in the Chinese context, the final scale contained 6 items after preresearch, with specific items such as "There are rules for distribution" and "The salary reflects the effort I put into my work".

Organizational CPSR: referring to the scale developed by Lin et al. (2018), some adjustments were made based on expert recommendations and the actual situation of the preresearch, and the final scale contained 16 items, with specific items such as "The cost control of the project is well implemented" and "The project management organization shows concern for pollution prevention and treatment (atmosphere, water, waste pollution, etc.)", etc.

Control variables: based on previous literature, the profitability, the size (the number of employees in the corporation) of the corporations involved in the construction, and the size of the project (excluding land sold by the government. " 1 " refers to below 10 million CNY, " 2 " refers to 10 to 50 million CNY, " 3 " refers to 50 to 100 million CNY, " 4 " refers to 100 to 300 million CNY, and " 5 " refers to over 300 million $\mathrm{CNY}$ ) were set as control variables.

3.2. Sample and Data Collection. As one of the new first-tier cities in China, Wuhan is being developed rapidly and attracts an abundant population from surrounding small cities. There are many construction projects of the house as the investment of real estate has reached 218.33 billion CNY in 2020, and there are also many office buildings, shopping malls, factories, and other projects, which provide qualified research samples. Before formally distributing the questionnaire, this research conducted a preresearch of 60 project management organizations, including owners, contractors, supervisors, designers, and suppliers. Based on the empirical results and feedback from the 60 valid preresearch samples, the questionnaire phrasing and question items were adjusted appropriately.

After the preresearch, formal data collection was carried out, and field research was conducted on completed and operational construction projects in Wuhan from January to April 2021. These projects, including real estate, office buildings, and factories, are mainly located downtowns, such as Guanggu, Jiangxia, and Hanyang. All projects are taken seriously by the local government, and they have a particular effect on surrounding communities and the environment. In the field research, the project managers who participated in the research were also invited to distribute the questionnaires to other colleagues through the questionnaire research platform, and 539 responses were collected in total. To ensure results' validity, reverse items were set for the questionnaires distributed through the online platform, and responses with a response time of fewer than 3 minutes were excluded. A total of 367 out of 539 responses were retained, with a proportion of $68.09 \%$.

Table 1 lists the general information of the interviewees. In the distribution of gender, $91.01 \%$ were male and $8.99 \%$ were female; from the perspective of working years, $78.75 \%$ of the respondents had worked for more than five years; in terms of positions, $47.96 \%$ of the respondents were in the position of technical director or above; among the types of respondent corporations, $82.64 \%$ were owners, contractors, and supervisors. These percentages reflect the actual distribution of construction project management organizations in China.

\section{Results}

4.1. Confirmative Factor Analysis. We used AMOS23.0 on the model with four key variables mentioned earlier to test the variables' validities. From Table 2 , the result shows $\chi^{2} / \mathrm{df}=1.819$, $\mathrm{TLI}=0.92$, and CFI $=0.91$, so the values of TLI and CFI are close to or higher than the suggested cutoff value of 0.9 . And RMSEA $=0.047$, which is also smaller than the cutoff value of 0.08. Thus, the model fits the data well [54]. Furthermore, the loadings of all factors are significant, with ranges from 0.616 to 0.891 , which are greater than 0.6 , and this indicates the validities are convergent.

From Table 3, there are significant correlations among PE's ethical leadership, employee's organizational identification, organizational justice, and the organizational CPSR, with values in the range $0.181-0.411$. Since all values are lower than the threshold of 0.85 , the square root of the AVE of each variable is greater than the correlation coefficients with other variables, which implies the variable discriminations.

4.2. Hypothesis Testing. The mediating effect of employee's organizational identification between the PE's ethical leadership and the organizational CPSR was examined in SPSS with Process macros (model 4) developed by Hayes 


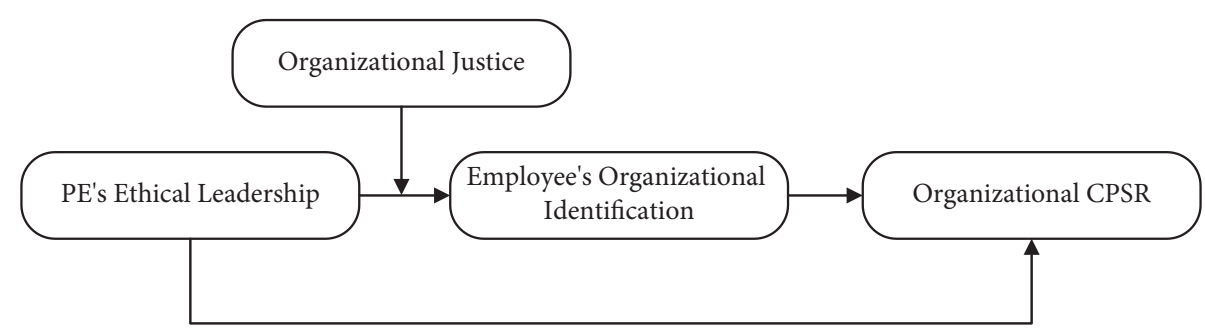

FIGURE 1: Conceptual model of organizational CPSR.

Table 1: Demographics of surveyed respondents.

\begin{tabular}{|c|c|c|c|}
\hline Category & Attribute & Count & Percentage \\
\hline \multicolumn{4}{|l|}{ Individual information } \\
\hline \multirow{2}{*}{ Gender } & Male & 334 & 91.01 \\
\hline & Female & 33 & 8.99 \\
\hline \multirow{3}{*}{ Work experience } & $1-5$ years & 78 & 21.25 \\
\hline & $5-10$ years & 136 & 37.06 \\
\hline & More than 10 years & 153 & 41.69 \\
\hline \multirow{4}{*}{ Education } & High school & 57 & 15.53 \\
\hline & Junior college & 109 & 29.70 \\
\hline & Bachelor & 172 & 46.87 \\
\hline & Master and above & 29 & 7.90 \\
\hline \multirow{5}{*}{ Position } & General manager & 13 & 3.54 \\
\hline & Project manager or division manager & 65 & 17.71 \\
\hline & Technical director & 98 & 26.70 \\
\hline & Engineer & 169 & 46.05 \\
\hline & Other & 31 & 8.45 \\
\hline \multirow{5}{*}{ Types of respondent corporations } & Owner & 76 & 20.71 \\
\hline & Contractor & 178 & 48.50 \\
\hline & Supervisor & 86 & 23.43 \\
\hline & Designer & 21 & 5.72 \\
\hline & Supplier & 15 & 4.09 \\
\hline
\end{tabular}

(2012), controlling corporate profitability, corporate size, and project size. The results (Table 4 ) show there is a significant predictive effect of the PE's ethical leadership on the organizational CPSR $(B=0.268, t=6.632, P<0.001)$, and thus the hypothesis $\mathrm{H} 1$ is verified. After adding the mediating variables, the direct predictive effect of the PE's ethical leadership on the organizational CPSR remains significant ( $B=0.189, t=4.396, P<0.001)$, and the predictive effect of the PE's ethical leadership on employee's organizational identification $(B=0.350, t=8.461, P<0.001)$ and the effect of employee's organizational identification on the organizational CPSR $(B=0.224, t=2.483, P<0.01)$ are also significantly positive. Additionally, the bootstrap $95 \%$ confidence intervals for the direct effect of the PE's ethical leadership on the organizational CPSR and the mediating effect of employee's organizational identification do not contain 0 (Table 5), indicating that the PE's ethical leadership not only predicts the organizational CPSR directly but also predicts the organizational CPSR through the mediating effect of employee's organizational identification. Therefore, hypothesis $\mathrm{H} 2$ is verified. Moreover, the direct and indirect effects $(0.189,0.078)$ accounted for $70.71 \%$ and $29.29 \%$ of the total effect (0.268).
Next, model 7 in the Process macro (consistent with the conceptual model of this research) was adopted to test the moderated mediation model, controlling the corporate profitability, corporate size, and project size. The result (Table 6) shows that the interaction item between the PE's ethical leadership and organizational justice predicts employee's organizational identification effectively after adding organizational justice into the model $(B=0.14, t=2.775$, $P<0.01$ ), indicating that organizational justice moderates the predictive effect of the PE's ethical leadership on employee's organizational identification. Thus, hypothesis $\mathrm{H} 3$ was verified. With a simple slope analysis (Figure 2), employee's organizational identification is influenced most positively by PE's ethical leadership for respondents with a low sense of organizational justice (M-1SD), but its effect is smaller than respondents with a high sense of organizational justice $(M+1 S D)$. In addition, at the three levels of organizational justice, the mediating effect of employee's organizational identification in the relationship between the PE's ethical leadership and the organizational CPSR tends to gradually increase (Table 7), that is, as the level of organizational justice increases, the PE's ethical leadership is more likely to promote the organizational CPSR by enhancing 
TABle 2: Measurement model.

\begin{tabular}{|c|c|c|}
\hline Construct/item & Loading & $t$-value \\
\hline \multicolumn{3}{|l|}{ PE's ethical leadership $(\alpha=0.94)$} \\
\hline 1. My executive conducts personal life in an ethical manner. & 0.771 & - \\
\hline 2. My executive defines success not just by results but also by process. & 0.697 & 14.080 \\
\hline 3. My executive listens to employees' suggestions. & 0.758 & 15.574 \\
\hline 4. My executive disciplines employees who violate ethical standards. & 0.838 & 17.634 \\
\hline 5. My executive makes fair and equitable evaluation to employees. & 0.739 & 15.090 \\
\hline 6. My executive can be trusted. & 0.812 & 16.938 \\
\hline 7. My executive discusses ethical and moral standards with employees. & 0.711 & 14.418 \\
\hline 8. My executive sets an example of how to do things the right way in terms of ethics. & 0.776 & 16.024 \\
\hline 9. My executive focuses on the interests of employees. & 0.871 & 18.521 \\
\hline 10. When making decisions, my executive asks "what is the right thing to do?" & 0.891 & 19.068 \\
\hline \multicolumn{3}{|l|}{ Employee's organizational identification $(\alpha=0.86)$} \\
\hline 1. When someone criticizes my project management organization, it feels like a personal insult. & 0.698 & - \\
\hline 2. I am very interested in what others think about my project management organization. & 0.756 & 13.036 \\
\hline 3. When I talk about my project management organization, I usually say "we" rather than "they". & 0.696 & 12.091 \\
\hline 4. The successes of my project management organization are my successes. & 0.616 & 10.792 \\
\hline 5. When someone praises my project management organization, it feels like a personal compliment. & 0.770 & 13.249 \\
\hline 6. If the media reported a negative story about my project management organization, I would & 0.785 & 13.467 \\
\hline
\end{tabular}

Organizational CPSR $(\alpha=0.91)$

Economic responsibility $(\alpha=0.85)$

1. The cost control of the project is well implemented.

2. The actual progress of the project is in line with the expected schedule. 13.075

3. The quality of the project is satisfactory.

4. New technologies or methodological innovations are adopted in the project. 11.138

5. The project fits the technical specifications and functional needs.

$0.756 \quad 13.174$

Legal responsibility $(\alpha=0.86)$

1. The project information is open and transparent.

2. The project rigorously follows the laws and regulations.

0.837

0.742

0.755

4. The project management organization believes that fair competition is important.

Ethical and environmental responsibility $(\alpha=0.84)$

1 . The project considers rational resource distribution and waste abatement.

2. The project management organization shows concern for safety and health of workers.

3. The project management organization shows concern for pollution prevention and treatment

(atmosphere, water, waste pollution, etc.).

4. The project management organization shows concern for ecological environment protection (energy saving, water saving, etc.).

Political responsibility $(\alpha=0.81)$

1. The project provides local job opportunities.

2. The project has a good relationship with the surrounding community.

3. The project takes part in local philanthropy.

Organizational justice $(\alpha=0.87)$

1. There are rules for distribution.

2. Distribution system is well implemented.

3. The distribution is open and transparent.

4. The salary reflects the effort I put into my work.

5. Compared with colleagues in the same job and position, my salary is reasonable.

6. I'm paid reasonably for my workload and responsibilities.

Note: model fit index: $\chi^{2}=1191.43, \chi^{2} / \mathrm{df}=1.819, \mathrm{TLI}=0.92, \mathrm{CFI}=0.91$, RMSEA $=0.047$.

employees' organizational identification. Finally, hypothesis $\mathrm{H} 4$ is verified.

\section{Discussion}

5.1. PE's Ethical Leadership. In this study, the PE's ethical leadership positively predicted the organizational CPSR. Previous research exploring the fulfillment of corporate social responsibility has shown that ethical leadership can effectively contribute to the formulation and fulfillment of contractors' corporate social responsibility strategies $[34,35,55]$. This study further expands the role of ethical leadership in the CPSR. The PE's ethical leadership can effectively promote the implementation of the organizational CPSR for two reasons mainly. First, PEs as the decision-makers of the project, their style of leadership will affect decision-making and results of the organization, especially when the management organizations of the 
TABLE 3: Means, standard deviations, and correlations of variables.

\begin{tabular}{|c|c|c|c|c|c|c|c|c|c|}
\hline & Mean & SD & 1 & 2 & 3 & 4 & 5 & 6 & 7 \\
\hline 1. Corporate profitability & 3.278 & 1.126 & - & & & & & & \\
\hline 2. Corporate size & 2.529 & 1.058 & -0.043 & - & & & & & \\
\hline 3. Project size & 3.019 & 1.238 & 0.000 & 0.021 & - & & & & \\
\hline 4. PE's ethical leadership & 3.584 & 0.938 & 0.063 & 0.035 & 0.011 & $(0.789)$ & & & \\
\hline 5.Employee's organizational identification & 3.656 & 0.818 & $0.165^{* *}$ & 0.036 & -0.013 & $0.411^{* * *}$ & $(0.722)$ & & \\
\hline 6. Organizational justice & 3.802 & 0.752 & 0.001 & -0.013 & -0.055 & $0.340^{* * *}$ & $0.327^{* * *}$ & $(0.729)$ & \\
\hline 7. Organizational CPSR & 3.525 & 0.782 & $0.206^{* *}$ & 0.084 & -0.034 & $0.336^{* * *}$ & $0.357^{* * *}$ & $0.181^{* * *}$ & $(0.755)$ \\
\hline
\end{tabular}

Note: (1) $N=367 ; * * P<0.01 ; * * * P<0.001$, below is the same as above. (2) The square root of AVE for discriminant validity is in parentheses along the diagonal.

TABLE 4: Results of mediation analyses.

\begin{tabular}{|c|c|c|c|c|c|c|}
\hline \multirow[t]{2}{*}{ Variable } & \multicolumn{2}{|c|}{$\begin{array}{l}\text { Employee's } \\
\text { organizational } \\
\text { identification }\end{array}$} & \multicolumn{2}{|c|}{ Organizational CPSR } & \multicolumn{2}{|c|}{ Organizational CPSR } \\
\hline & B & $\mathrm{t}$ & $\mathrm{B}$ & $\mathrm{t}$ & $\mathrm{B}$ & $\mathrm{t}$ \\
\hline Corporate profitability & $0.102^{* *}$ & 2.964 & $0.132^{* * *}$ & 3.909 & $0.109^{* *}$ & 3.273 \\
\hline Corporate size & 0.022 & 0.595 & 0.061 & 1.698 & 0.056 & 1.601 \\
\hline Project size & -0.012 & -0.388 & -0.025 & -0.824 & -0.022 & -0.754 \\
\hline PE's ethical leadership & $0.350^{* * *}$ & 8.461 & $0.268^{* * *}$ & 6.632 & $0.189^{* * *}$ & 4.396 \\
\hline Employee's organizational identification & & & & & $0.224^{* *}$ & 2.483 \\
\hline$R^{2}$ & \multicolumn{2}{|c|}{0.190} & \multicolumn{2}{|c|}{0.155} & \multicolumn{2}{|c|}{0.200} \\
\hline $\mathrm{F}$ & \multicolumn{2}{|c|}{21.159} & \multicolumn{2}{|c|}{16.628} & \multicolumn{2}{|c|}{18.022} \\
\hline$P$-value sig. & \multicolumn{2}{|c|}{$<0.001$} & \multicolumn{2}{|c|}{$<0.001$} & \multicolumn{2}{|c|}{$<0.001$} \\
\hline
\end{tabular}

TABle 5: Total effect, direct effect, and indirect effect.

\begin{tabular}{lccccc}
\hline & Effect & Boot SE & Boot LLCI & Boot ULCI & 0.130 \\
Indirect effect & 0.078 & 0.025 & 0.029 & 0.269 & 29.29 \\
Direct effect & 0.189 & 0.042 & 0.105 & 0.354 & 70.71 \\
Total effect & 0.268 & 0.048 & 0.169 & $\%)$ \\
\hline
\end{tabular}

Note: bootstrap sample size $=5000 ; \mathrm{SE}=$ standard error; $\mathrm{LLCI}=$ lower limit in $95 \%$ confidence interval; $\mathrm{ULCI}=$ upper limit in $95 \%$ confidence interval, below is the same as above.

TABLE 6: Results of moderation analyses.

\begin{tabular}{|c|c|c|c|c|}
\hline \multirow[t]{2}{*}{ Variable } & \multicolumn{2}{|c|}{$\begin{array}{c}\text { Employee's organizational } \\
\text { identification }\end{array}$} & \multicolumn{2}{|c|}{ Organizational CPSR } \\
\hline & B & $\mathrm{t}$ & $\mathrm{B}$ & $\mathrm{t}$ \\
\hline Corporate profitability & $0.106^{* *}$ & 3.165 & $0.109^{* *}$ & 3.273 \\
\hline Corporate size & 0.030 & 0.853 & 0.056 & 1.601 \\
\hline Project size & -0.006 & -0.203 & -0.022 & -0.754 \\
\hline PE's ethical leadership & $0.309^{* * *}$ & 7.114 & $0.189^{* * *}$ & 4.396 \\
\hline Employee's organizational identification & & & $0.224^{* *}$ & 2.483 \\
\hline Organizational justice & $0.212^{* * *}$ & 3.937 & & \\
\hline PE's ethical leadership $\times$ organizational justice & $0.140^{* *}$ & 2.775 & & \\
\hline$R^{2}$ & \multicolumn{2}{|c|}{0.247} & \multicolumn{2}{|c|}{0.200} \\
\hline $\mathrm{F}$ & \multicolumn{2}{|c|}{19.669} & \multicolumn{2}{|c|}{18.022} \\
\hline$P$-value sig. & \multicolumn{2}{|c|}{$<0.001$} & \multicolumn{2}{|c|}{$<0.001$} \\
\hline
\end{tabular}

construction project, composed of personnel from different departments and professions from multiple corporations, have the characteristics of organizational temporariness and team diversity $[37,38]$. As the people in charge of participating corporations in the project, PEs have more considerable discretionary power than executives at the corporate level so that their decisions can directly determine the degree of the implementation of organizational CPSR. The higher the PE's ethical leadership level, the more they are concerned about the negative social impacts caused by construction projects. So in decision-making, they consider more about the project itself, such as improving project quality, reducing construction costs, and minimizing the impact on the surrounding environment, which is conducive to promoting 


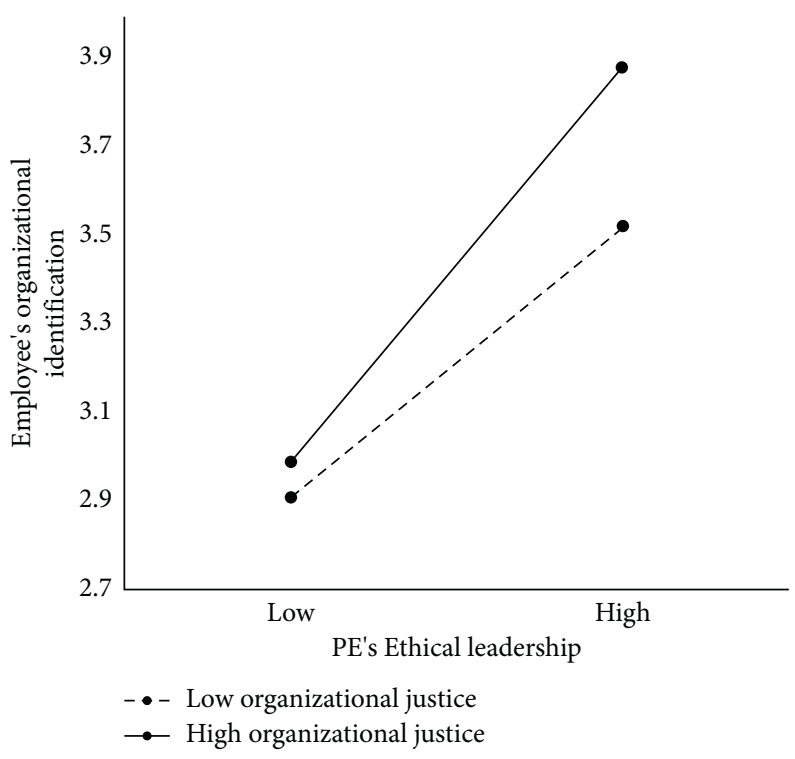

FIgUre 2: Slope analysis.

TABle 7: Mediating effects at different levels of organizational justice.

\begin{tabular}{cccccc}
\hline & Condition & Effect & Boot SE & Boot LLCI & Boot ULCI \\
\hline \multirow{3}{*}{ Organizational justice } & M-1SD & 0.046 & 0.021 & 0.007 & 0.090 \\
& M & 0.069 & 0.025 & 0.023 & 0.119 \\
& $M+1 S D$ & 0.093 & 0.035 & 0.028 & 0.165 \\
\hline
\end{tabular}

the implementation of organizational CPSR, rather than their gains and losses. Secondly, the higher the level of the PE's ethical leadership, the more they meet the criteria of an ethical manager who has a broad ethical consciousness, emphasizes managing ethically, sets ethical standards in the organization, disciplines the behavior of organization members, and takes the lead in complying with rules and regulations $[40,41]$. So that the entire project management organization also complies better with the requirements of legal norms in the project construction process, which reduces the occurrence of accidents of project, conflicts of community, violations of labor rights, and other problems.

In previous researches, researchers have mentioned considering the individual behavior of PE in the CPSR seriously, as the social responsibility is informal, immature, and compliance driven to a considerable extent in the construction industry, and it is challenging to implement without institutional pressure [56]. At the same time, the lack of the CPSR is multifaceted, and the institutional pressures and characteristics of participating corporations are essential factors of implementation of the CPSR, where the values and personal characteristics of PEs are critical factors affecting the CPSR implementation, and the vision, mission, and leadership style of PEs are crucial elements in solving organizational problems [57]. Therefore, when selecting project leaders, corporations involved in project construction should focus on leaders' ethical concepts and moral standards, instruct them to lead ethically, reduce the information asymmetry through strategy construction and project evaluation, narrow the space for PE's moral risks, and promote ethical leadership of PE from both incentive and constraint aspects [58].

5.2. Employee's Organizational Identification and Organizational Justice. Employee's organizational identification partially mediates between the PE's ethical leadership and the organizational CPSR. This statement suggests that the PE's ethical leadership can directly predict the organizational CPSR since PEs determine the strategic orientation of the entire organization during the construction process. If the level of the PE's ethical leadership is high, the organization's strategy will be more inclined to implement the CPSR. The PE's ethical leadership can also predict the organizational CPSR through the mediating role of employees' organizational identification. On a practical level, PEs with a higher level of ethical leadership as ethical individuals value the interests of employees more and act as ethical role models with the qualities of sincerity and reliability in the organization, which close the psychological distance between PEs and employees, promote the generation of employees' sense of belonging in the organization, and help maintain a stable and harmonious relationship between PEs and employees [44]. In addition, employees involved in project management, as an important part of the implementation process of the organizational CPSR, will contribute to increased dedication to their work and proactive and responsible behavior with a high level of organizational 
identification [48]. In the actual work of project management, they will pay more attention to the project construction quality and issues such as pollution prevention and ecological protection, thus promoting the implementation of the organizational CPSR. The results of the study suggest that the organizational identification of employees involved in project management is significant in the implementation process of the organizational CPSR and that PEs should be promoted and supervised to lead ethically so that they value the interests of their employees and enhance their organizational identification, thus promoting the implementation of the organizational CPSR. With low organizational identification, employees participate less actively in project management, and only when they have an unquestionable loyalty and identification with the organization, they are more inclined to participate with responsible behavior [47]. Previous studies have shown that PEs should help employees realize what they should do in the implementation process of the CPSR and enhance the organizational identification of members by motivating spiritually and materially to improve the performance of the CPSR ultimately [59]. Therefore, project management organizations should support and concern the employees in career planning and personal development, as well as advocate and urge PEs to lead ethically, which helps employees identify with the organization since employees with high organizational identification are more positive and responsible at work with more emotional commitment, which can effectively improve the implementation of the CPSR.

Organizational justice moderates the relationship between the PE's ethical leadership and employees' organizational identification. As we mentioned earlier, PE's ethical leadership promotes employees' organizational identification mainly because PE values employees' interests and ethical models, shortening the psychological distance between PEs and employees. Then, on the other hand, organizational justice ensures employees' demand for material life. When there is a high level of organizational justice, the distribution system is usually transparent and well implemented. Furthermore, employees are usually compensated according to their duties and workload. In this environment, employees will be more satisfied with the organization's distribution system and compensation package, which benefits the generation of their organizational identification more. Therefore, in an environment with a high level of organizational justice, the PE's ethical leadership can predict employee's organizational identification more significantly and promote the implementation of the CPSR more easily by promoting employee's organizational identification. Maintaining distributive and procedural fairness in project management organizations is vital since employees usually develop negative attitudes and antiproductive behaviors when they feel unfairly treated [60]. Also, employees who are seriously involved in project management should be given appropriate material incentives, as only when they feel rewarded for their efforts will they be more likely to agree and fulfill the decisions made in the organization and ultimately improve the CPSR.

\section{Conclusion}

With sustainable development being a concern for governments and project stakeholders, the appeal for projects to implement their social responsibility is growing; on the other hand, scholars have appealed for further investigation of the intrinsic mechanisms affecting the CPSR to achieve sustainable development. Based on upper echelons theory and affective events theory and adapted PE's leadership style to the implementation of organizational CPSR, this study examines the role of PE's ethical leadership and employee's organizational identity, as well as organizational justice, using data collected from field research questionnaire in Wuhan and online platforms by applying the Process macro in SPSS.

In this empirical study, we found that PE's ethical leadership has a significant positive effect on implementing the organizational CPSR. Therefore, when selecting the person in charge of the project's management organization, construction industry corporations should focus on examining their ethical level and conduct systematic training before they are formally employed to promote their awareness of social responsibility, enhance their ethical concepts and moral level, and guide them to lead ethically. Meanwhile, the discretion of PEs should be restrained through institutional construction. The fulfillment of social responsibility strategies and the occurrence of information asymmetry should also be tested and reduced with project evaluation to narrow the space for PE's moral risks.

We also found that the organizational identification of employees involved in project management plays a role in mediating the relationship between the PE's ethical leadership and the organizational CPSR, and the effect increases as the level of organizational justice rise. This shows that employees involved in project management significantly affect the implementation of the organizational CPSR. Therefore, it is imperative to take advantage of the interaction between the PE's ethical leadership and the employee's organizational identification to improve the PE's ethical leadership effectively, shorten the psychological distance between PEs and employees, and maintain an excellent ethical climate in the project management organization. In addition, we should ensure that the distribution system in the project management organization is open and transparent. For the employees responsible for the management and bearing a heavy workload, their remuneration should be gradually improved with appropriate material incentives to realize the organizational CPSR effectively.

This research fulfills the practice of social responsibility from the leader's level, increases the range of application of ethical leadership, and emphasizes the role of project participants in the implementation of CPSR. The CPSR can be better implemented through effective selection of PE considering ethical leadership, reduction of PE's discretion by regulation and evaluation, and protection of employees' rights. There are also some limitations. Firstly, the data came from a cross-sectional research design, and the results of this research cannot be used strictly to infer causality. Future researches could adopt longitudinal studies to enhance the 
persuasiveness of causal relationships between variables. Secondly, the management organization of the project is an integral part of project management, so its implementation of CPSR can, to a certain extent, represent the implementation of CPSR on the whole project. Although this research focuses on the internal mechanism of CPSR in project management organizations and examines the interaction of the PE's ethical leadership and employee's organizational identification on the organizational CPSR, it does not consider the dynamics and complexity of projects and the heterogeneity of stakeholders. The future research can take the whole construction project as the research perspective and research on the CPSR in the form of a multilevel combination of the institution, background of participating corporations, and individual characteristics. The realization of sustainable development of the project is vital despite its complexity.

\section{Data Availability}

The data used to support the findings of this study are available from the corresponding author on request.

\section{Conflicts of Interest}

The authors declare that they have no conflicts of interest.

\section{Acknowledgments}

The authors are grateful for the support from the MOE (Ministry of Education of China) Project of Humanities and Social Sciences Research (grant no. 19YJA630035) and the International Collaborative Research Fund for Young Scholars in the Innovation Demonstration Base of Ecological Environment Geotechnical and Ecological Restoration of Rivers and Lakes.

\section{References}

[1] S. X. Zeng, H. Y. Ma, H. Lin, R. C. Zeng, and V. W. Y. Tam, "Social responsibility of major infrastructure projects in China," International Journal of Project Management, vol. 33, no. 3, pp. 537-548, 2015.

[2] H. Lin, S. Zeng, H. Ma, R. Zeng, and V. W. Y. Tam, "An indicator system for evaluating megaproject social responsibility," International Journal of Project Management, vol. 35, no. 7, pp. 1415-1426, 2017.

[3] E. A. M. Bevan and P. Yung, "Implementation of corporate social responsibility in Australian construction SMEs," Engineering Construction and Architectural Management, vol. 22, no. 3, pp. 295-311, 2015.

[4] S. Bice, "Bridging corporate social responsibility and social impact assessment," Impact Assessment and Project Appraisal, vol. 33, no. 2, pp. 160-166, 2015.

[5] L. Wang, G. Jia, and N. Mackhaphonh, "Case study on improving the effectiveness of public participation in public infrastructure megaprojects," Journal of Construction Engineering and Management, vol. 145, no. 4, Article ID 05019003 , 2019.

[6] G. Wang, Q. He, X. Meng, G. Locatelli, T. Yu, and X. Yan, "Exploring the impact of megaproject environmental responsibility on organizational citizenship behaviors for the environment: a social identity perspective," International Journal of Project Management, vol. 35, no. 7, pp. 1402-1414, 2017.

[7] B. Xia, A. Olanipekun, Q. Chen, L. Xie, and Y. Liu, "Conceptualising the state of the art of corporate social responsibility (CSR) in the construction industry and its nexus to sustainable development," Journal of Cleaner Production, vol. 195, pp. 340-353, 2018.

[8] H. Ma, Z. Liu, S. Zeng, H. Lin, and V. W. Y. Tam, "Does megaproject social responsibility improve the sustainability of the construction industry?" Engineering Construction and Architectural Management, vol. 27, no. 4, pp. 975-996, 2019.

[9] Q. He, X. Chen, G. Wang et al., "Managing social responsibility for sustainability in megaprojects: an innovation transitions perspective on success," Journal of Cleaner Production, vol. 241, Article ID 118395, 2019.

[10] Z. Liu, Y. Sui, Z. Jin, and X. Yang, "Evaluation of major infrastructure project's social responsibility: from a global perspective," Journal of Systems Management, vol. 27, no. 1, pp. 101-108, 2018, in Chinese.

[11] L. Xie, T. Han, H. Chu, and B. Xia, "Behavior selection of stakeholders toward megaproject social responsibility: perspective from social action theory," Advances in Civil Engineering, vol. 2019, Article ID 4956067, 12 pages, 2019.

[12] L. Xie, T. Ju, and B. Xia, "Institutional pressures and megaproject social responsibility behavior: a conditional process model," Buildings, vol. 11, no. 4, p. 140, 2021.

[13] S. Lichtenstein, E. Badu, D. Owusu-Manu, D. J. Edwards, and G. D. Holt, "Corporate social responsibility architecture and project alignments: a study of the Ghanaian construction industry," Journal of Engineering, Design and Technology, vol. 11, no. 3, pp. 334-353, 2013.

[14] Z. Zhou and C. Mi, "Social responsibility research within the context of megaproject management: trends, gaps and opportunities," International Journal of Project Management, vol. 35, no. 7, pp. 1378-1390, 2017.

[15] A. Alotaibi, F. Edum-Fotwe, and A. D. F. Price, "Critical barriers to social responsibility implementation within megaconstruction projects: the case of the kingdom of Saudi arabia," Sustainability, vol. 11, no. 6, p. 1755, 2019.

[16] L. Xie, T. Xu, A. Ji, and Y. Le, "Research on the influence of project manager traits on the performance of engineering social responsibility," Construction Economy, vol. 40, no. 2, pp. 111-115, 2019, in Chinese.

[17] H. Lin, Y. Sui, H. Ma, L. Wang, and S. Zeng, "CEO narcissism, public concern, and megaproject social responsibility: moderated mediating examination," Journal of Management in Engineering, vol. 34, no. 4, pp. 1-10, 2018.

[18] G. P. Li and X. Q. Wei, "Definition, measurements and economic consequences of corporate social responsibility: a survey on theories of corporate social responsibility," Accounting Research, vol. 8, pp. 33-40, 2014, in Chinese.

[19] A. B. Carroll, "Corporate social responsibility: evolution of a definitional construct," Business \& Society, vol. 38, no. 3, pp. 268-295, 1999.

[20] B. Flyvbjerg, "What you should know about megaprojects and why: an overview," Project Management Journal, vol. 45, no. 2, pp. 6-19, 2014.

[21] G. Locatelli, P. Littau, N. J. Brookes, and M. Mancini, "Project characteristics enabling the success of megaprojects: an empirical investigation in the energy sector," Procedia - Social and Behavioral Sciences, vol. 119, pp. 625-634, 2014.

[22] Y. Hu, A. P. C. Chan, Y. Le, and R. Jin, "From construction megaproject management to complex project management: 
bibliographic analysis," Journal of Management in Engineering, vol. 31, no. 4, Article ID 04014052, 2015.

[23] X. Zheng, Y. Lu, Y. Le, Y. Li, and J. Fang, "Formation of interorganizational relational behavior in megaprojects: perspective of the extended theory of planned behavior," Journal of Management in Engineering, vol. 34, no. 1, Article ID 04017052, 2018.

[24] G. Wang, Q. He, B. Xia, X. Meng, and P. Wu, "Impact of institutional pressures on organizational citizenship behaviors for the environment: evidence from megaprojects," Journal of Management in Engineering, vol. 34, no. 5, Article ID 04018028, 2018.

[25] Q. He, L. Luo, Y. Hu, and A. P. C. Chan, "Measuring the complexity of mega construction projects in China-a fuzzy analytic network process analysis," International Journal of Project Management, vol. 33, no. 3, pp. 549-563, 2015.

[26] A. Alotaibi, F. Edum-Fotwe, and A. Price, "Identification of social responsibility factors within mega construction projects," International Journal of Mechanical Engineering Education, vol. 13, no. 1, pp. 14-27, 2019.

[27] X. Lin, C. M. Ho, and G. Q. Shen, "For the balance of stakeholders' power and responsibility," Management Decision, vol. 56, no. 3, pp. 550-569, 2018.

[28] M. E. Uribe Macías, "Analysis of construction projects stakeholders from corporate social responsibility," Cuadernos de Administración, vol. 33, no. 58, pp. 58-76, 2018.

[29] Z. Zhao, X. Zhao, J. Zuo, and G. Zillante, "Corporate social responsibility for construction contractors: a China study," Journal of Engineering, Design and Technology, vol. 14, no. 3, pp. 614-640, 2016.

[30] X. Lin, C. M. F. Ho, and G. Q. P. Shen, "Who should take the responsibility? Stakeholders' power over social responsibility issues in construction projects," Journal of Cleaner Production, vol. 154, pp. 318-329, 2017.

[31] X. Lin, B. McKenna, C. M. F. Ho, and G. Q. P. Shen, "Stakeholders' influence strategies on social responsibility implementation in construction projects," Journal of Cleaner Production, vol. 235, pp. 348-358, 2019.

[32] A. A. Zahidy, S. Sorooshian, and Z. Abd Hamid, "Critical success factors for corporate social responsibility adoption in the construction industry in Malaysia," Sustainability, vol. 11, no. 22, p. 6411, 2019.

[33] A. Abdullah, S. Reza Mohandes, A. Rahim Abdul Hamid, and B. Singh, "The practices of corporate social responsibility among construction companies in Malaysia," Research Journal of Applied Sciences, Engineering and Technology, vol. 12, no. 7, pp. 742-755, 2016.

[34] S. Mayr, "Corporate social responsibility in SMEs: the case of an Austrian construction company," International Journal of Business Research, vol. 15, no. 2, pp. 61-72, 2015.

[35] X. Li, X. Gao-Zeller, T. E. Rizzuto, and F. Yang, "Institutional pressures on corporate social responsibility strategy in construction corporations: the role of internal motivations," Corporate Social-Responsibility and Environmental Management, vol. 26, no. 4, pp. 721-740, 2019.

[36] C. Zheng, J. Feng, Q. Lu, K. Zhang, and S. Xue, “An empirical research on the matching relationships between relationship governance and contractual governance orientation from the viewpoint of life cycle---taking PPP projects as an example," Management Review, vol. 29, no. 12, pp. 258-268, 2017, in Chinese.

[37] R. A. Lundin and A. S. Derholm, "A theory of the temporary organization," Scandinavian Journal of Management, vol. 11, no. 4, pp. 437-455, 1995.
[38] J. Larsson, P. E. Eriksson, T. Olofsson, and P. Simonsson, "Leadership in Civil engineering: effects of project managers' leadership styles on project performance," Journal of Management in Engineering, vol. 31, no. 6, Article ID 04015011, 2015.

[39] D. C. Hambrick and P. A. Mason, "Upper echelons: the organization as a reflection of its top managers," Academy of Management Review, vol. 9, no. 2, pp. 193-206, 1984.

[40] L. K. Trevino, M. E. Brown, and L. P. Hartman, "A qualitative investigation of perceived executive ethical leadership: perceptions from inside and outside the executive suite," Human Relations, vol. 56, no. 1, pp. 5-37, 2003.

[41] M. E. Brown, L. K. Trevino, and D. A. Harrison, "Ethical leadership: a social learning perspective for construct development and testing," Organizational Behavior and Human Decision Processes, vol. 97, no. 2, pp. 117-134, 2005.

[42] F. Mael and B. E. Ashforth, "Alumni and their alma mater: a partial test of the reformulated model of organizational identification," Journal of Organizational Behavior, vol. 13, no. 2, pp. 103-123, 1992.

[43] M. Riketta, "Organizational identification: a meta-analysis," Journal of Vocational Behavior, vol. 66, no. 2, pp. 358-384, 2005.

[44] J. M. Morgan, C. M. Reynolds, T. J. Nelson, A. R. Johanningmeier, M. Griffin, and P. Andrade, "Tales from the fields: sources of employee identification in agribusiness," Management Communication Quarterly An International Journal, vol. 17, no. 3, pp. 360-395, 2004.

[45] M. G. Pratt and R. J. B. Kaufmann, "Constructing professional identity: the role of work and identity learning cycles in the customization of identity among medical residents," Academy of Management Journal, vol. 49, no. 2, pp. 235-262, 2006.

[46] E. S. Lee, T. Y. Park, and B. Koo, "Identifying organizational identification as a basis for attitudes and behaviors: a metaanalytic review," Psychological Bulletin, vol. 141, no. 5, pp. 1049-1080, 2015.

[47] L. Ma, J. Jiao, A. Chen, and H. Jiang, "Differentiating organizational identification and dis-identification of employees through A nomological network," Acta Psychology Sinica, vol. 43, no. 3, pp. 106-121, 2011, in Chinese.

[48] R. Li, Z. Y. Zhang, and X. M. Tian, "Can self-sacrificial leadership promote subordinate taking charge? The mediating role of organizational identification and the moderating role of risk aversion," Journal of Organizational Behavior, vol. 37, no. 5, pp. 214-216, 2016.

[49] H. Jian, Y. Xu, M. Cao, and S. Zhao, "Research on the relationship between inclusive leadership and employee engagement: based on an organizational identification perspective," Chinese Journal of Management, vol. 14, no. 11, pp. 1624-1630, 2017, in Chinese.

[50] S. S. Masterson, K. Lewis, B. M. Goldman, and P. Simonsson, "Integrating justice and social exchange: the different effects of fair procedures and treatment on work relationships," Academy of Management Journal, vol. 43, no. 4, pp. 738-748, 2020.

[51] S. Fox, P. E. Spector, and D. Miles, "Counterproductive work behavior $(\mathrm{CWB})$ in response to job stressors and organizational justice: some mediator and moderator tests for autonomy and emotions," Journal of Vocational Behavior, vol. 59, no. 3, pp. 291-309, 2001.

[52] Z. Wen and B. Ye, "Analyses of mediating effects: the development of methods and models," Advances in Psychological Science, vol. 22, no. 5, pp. 731-745, 2014, in Chinese. 
[53] Y. Liu, L. Ling, and Y. Li, "Effect of organizational justice perception on organizational effectiveness variables," Management World, vol. 3, pp. 126-132, 2003, in Chinese.

[54] J. F. Hair, Multivariate Data Analysis: A Global Perspective, Prentice-Hall, Hoboken, NJ, USA, 7th ed. edition, 2009.

[55] L. Wu, H. K. Kwan, F. H. Yim, R. K. Chiu, and X. He, "CEO ethical leadership and corporate social responsibility: a moderated mediation model," Journal of Business Ethics, vol. 130, no. 4, pp. 819-831, 2015.

[56] M. Loosemore and B. T. H. Lim, "Mapping corporate social responsibility strategies in the construction and engineering industry," Construction Management \& Economics, vol. 36, no. 2, pp. 67-82, 2018.

[57] J. Storey, "What next for strategic-level leadership research?" Leadership, vol. 1, no. 1, pp. 89-104, 2005.

[58] L. Ma and P. Zhang, "Game analysis on moral hazard of construction project managers in China," International Journal of Civil Engineering, vol. 12, no. 4, pp. 429-438, 2014.

[59] X. Wang, W. Lai, C. Lu, and W. Xue, "Research on social responsibility behavior preference of construction enterprises based on stakeholder theory," in Proceedings of the International Conference on Construction and Real Estate Management, Guangzhou, China, November 2017.

[60] D. A. Jones, "Getting even with one's organization: relationships among types of injustice, desire for revenge, and counterproductive work behaviors," Journal of Organizational Behavior, vol. 30, no. 4, pp. 525-542, 2009. 